\title{
Social media in public health: is it used and is it useful?
}

\author{
Thomy Tonia
}

Published online: 1 November 2014

(C) Swiss School of Public Health 2014

Keywords Social media - Public health · Twitter . Altmetrics · Facebook · Blogs

In 2013, Oxford Dictionary declared the word "selfie" word of the year (Oxford Dictionaries 2013). Social media (SM)-related words received similar titles in the past (Sumners 2010): "unfriend", "twitter" and "hashtag" to name a few (Oxford University Press Blog 2009; Global Language Monitor 2013).

This confirms the degree of SM Table 1 penetration in our lives: 1.28 billion people use Facebook and 255 million use twitter (Smith 2014). The number of scientists that use SM, however, is difficult to estimate. A study found that 1 in 40 academics from 5 US and UK universities had a twitter account (Priem et al. 2012), while another reported that $13 \%$ of researchers use some sort of social networking at least once per week (Research Information Network 2010). Scholars are reluctant to use twitter generally but are more likely to do so during a conference (Mahrt et al. 2014). The use of twitter, moreover, seems to differ between academic disciplines. The use of SM amongst scientists is increasing but remains limited (Bik and Goldstein 2013); age is not a good predictor of its use (Rowlands et al. 2011).

In public health $(\mathrm{PH}), \mathrm{SM}$ is widely used by leading institutions, and some well-respected professors. A review looked at how institutions and individuals use SM for $\mathrm{PH}$ science communication (Bjerglund-Andersen and Söderqvist 2012) and found that they use them for research dissemination, discussions and networking, teaching and

T. Tonia $(\bowtie)$

Institute of Social and Preventive Medicine, University of Bern,

Bern, Switzerland

e-mail: ttonia@ispm.unibe.ch research. Other studies have highlighted the importance of using SM for health communication and surveillance (Kass-Hout and Alhinnami 2013), knowledge translation (Mairs et al. 2013) and networking (Roman 2014). Using SM has a potentially high number of benefits for researchers like rapid distribution of research, networking, etc. (Bjerglund-Andersen and Söderqvist 2012), but the reluctance to use them seems to arise from lack of control, difficulty in assessing benefits and distrust due to lack of formal peer review (Bjerglund-Andersen and Söderqvist 2012; Research Information Network 2010). Moreover, SM are susceptible to negative effects, like false accusations or harmful criticism (Bjerglund-Andersen and Söderqvist 2012; Künzli 2014; McKee 2014), which might make them less attractive to scientists.

Scientific journals are increasingly using SM, ranging from adding "share" options under the online versions of their papers, to actively maintaining SM profiles or even writing a full editorial using previous tweets (Nature Chemistry 2013). Journals use SM to disseminate their papers and network with authors, and readers. Nowadays, passive dissemination is a poor strategy, according to Darling et al. (2013): twitter can present an echo chamber for dissemination, especially when a paper gets retweeted. About $40 \%$ of twitter citations of papers occur within 1 week of publication, while half of them include a direct link to a resource (Priem and Costello 2010). Moreover, dissemination via SM can result in what Ogden (2013) calls "social-media facilitated peer review". Via twitter, papers can also reach people in decision making positions, while conference live tweeting might bring exposure of research to journalists. Some journals require authors to provide a tweetable abstract for their submission (Darling et al. 2013); furthermore, scientific societies have issued guidelines for citing SM (Roman 2014). 
The spread of SM resulted in research that attempts to measure their impact on scientific papers. One scientist noticed an increase in downloads of papers she tweeted about (Terras 2012). Eysenbach (2011) found that tweetation status (highly vs less tweeted papers) is a good predictor of citation status: highly tweeted papers were 11 times more likely to be highly cited. Citations and tweetations, however, seem to measure different concepts, namely scholarly versus social impact.

Another study (Haustein et al. 2014) found that $9.4 \%$ of about four million published PubMed papers have been tweeted at least once. Correlations were low, showing the difference between the two impact metrics. There were some differences between journals and specialties. Public Health had twitter coverage of $12.2 \%$ and the correlation between number of tweets and number of citations was significant.

Altmetrics, a term first described by Priem et al. (2010), describes the number of mentions of scientific papers in SM, traditional media and online reference management tools (Costas et al. 2014). These types of metrics aim to compliment traditional citation metrics and are incorporated more and more on the Journals' websites (including International Journal of Public Health).

IJPH has a strong SM presence: we host a blog since 2011 and Facebook and Twitter accounts since 2012. We got involved in SM to explore new opportunities for communicating with our readers and colleagues. This corresponds to our mission to "provide a thoughtful forum for contemporary issues and challenges in global public health research and practice". The study by Haustein et al. (2014) reports that the coverage of scientific papers on twitter has greatly increased over time, with more than $20 \%$ of papers published in 2012 receiving at least one tweet. Similarly, research on SM and PH is also increasing: A quick search in PubMed on "social media" and "public health" in the titles and abstracts of papers shows that there were 3 publications in 2009 meeting these criteria. This number rose to 22 in 2012 and escalated to 51 in 2013.

It seems that $\mathrm{SM}$ are more and more used in $\mathrm{PH}$. Whether they are useful or not depends on how "usefulness" is defined and how it is measured: societal impact should be measured in addition to scholarly impact, as public health is a field that per definition should have social impact. As a lot of the evidence for the impact of SM is still anecdotal (Bik and Goldstein 2013), we echo Moorhead's suggestion (Moorhead et al. 2013), namely that further research is needed with more robust methodologies and possibly RCTs to determine the role and effectiveness of SM for health care communication. We are excited about the results of such endeavours while at the same time we are trying to contribute to research ourselves (more on this soon). In the meantime, we are awaiting the announcement
Table 1 Social media mentioned in this Editorial

Type of social Description

media

$\mathrm{B} \log$

Posts usually revolve around one theme. They can be lengthy and contain images and links to other resources; they are usually displayed in reverse chronological order. Readers can usually comment (but comments can be moderated)

Facebook Profile pages that can be updated with text, pictures and links. Allows readers to comment and share content of their own. Choice of either personal profiles (with "friends") or institution/journal profiles (with "likes")

Twitter Short posts of up to 140 characters; can contain pictures and links to online sources. Readers may reply to posts and reproduce them (retweet)

For a comprehensive overview of different types of social media, please see Bjerglund-Andersen, Söderqvist (2012) Social Media and Public Health Research. University of Copenhagen, Faculty of Science. http://www.bjerglund.files.wordpress.com/2012/11/final-socialmedia-and-public-health-research1.pdf

of next word of the year. Being part of SM seems to improve our chances to know what it means!

\section{References}

Bik H, Goldstein M (2013) An introduction to social media for scientists. PLoS Biol 11:e1001535

Bjerglund-Andersen N, Söderqvist T (2012) Social Media and Public Health Research. University of Copenhagen, Faculty of Science. http://www.bjerglund.files.wordpress.com/2012/11/final-socialmedia-and-public-health-research1.pdf. Accessed 26 May 2014

Chemistry Nature (2013) All you can tweet. Nat Chem 5:247

Costas R, Zahedi Z, Wouters PF (2014). Do 'altmetrics' correlate with citations? Extensive comparison of altmetric indicators with citations from a multidisciplinary perspective. Centre for Social Science and Technology Studies, Leiden University. http://www. arxiv.org/ftp/arxiv/papers/1401/1401.4321.pdf. Accessed 26 May 2014

Darling E, Shiffman D, Cote I, Drew J (2013) The role of Twitter in the life cycle of a scientific publication. Ideas Ecol Evol 6:32-43

Eysenbach G (2011) Can Tweets Predict Citations? Metrics of Social Impact Based on Twitter and Correlation with Traditional Metrics of Scientific Impact. J Med Internet Res 13:e123

Global Language Monitor (2013). The word of 2013: "404" followed by fail!, hashtag, @ pontifex and the Optic. http://www. languagemonitor.com/trending-words/404-is-the-top-wordtoxic-politics-the-top-phrase-pope-francis-the-top-name-of2013/. Accessed 26 May 2014

Haustein S, Peters I, Sugimoto C, Thelwall M, Lariviere V (2014) Tweeting biomedicine: an analysis of tweets and citations in the biomedical literature. J Asso Inf Sci Technolog 65:656-659

Kass-Hout T, Alhinnami H (2013) Social media in public health. British Medical Bulletin 1-20

Künzli N (2014) To e-smoke or not to e-smoke? Is that a question? Int J Public Health. doi:10.1007/s00038-014-0598-y

Mahrt M, Weller K, Peters I (2014) Twitter in scholarly communication. In: Weller K, Bruns A, Burgess J, Mahrt M, Puschmann C (eds) Twitter and society. Peter Lang, New York, pp 399-410 
Mairs K, McNeil H, McLeod J, Prorok J, Stolee P (2013) Online strategies to facilitate health-related knowledge transfer: a systematic search and review. Health Info Libr J 30:261-277

McKee M (2014) Electronic cigarettes: proceed with great caution. Int J Public Health. doi:10.1007/s00038-014-0589-z

Moorhead S, Hazlett D, Harrison L, Carroll J, Irwin A, Hoving C (2013) A new dimension of health care: systematic review of the uses, benefits and limitations of social media for health communication. J Med Internet Res 15:e85

Ogden L (2013) Tags, blogs, tweets: social media as science tool? Bioscience 63:148

Oxford Dictionaries (2013) The Oxford Dictionaries word of the year 2013 is... http://www.blog.oxforddictionaries.com/2013/11/ word-of-the-year-2013-winner/. Accessed 26 May 2014

Oxford University Press Blog (2009) Oxford word of the year 2009: unfriend. http://www.blog.oup.com/2009/11/unfriend/. Accessed 26 May 2014

Priem J, Costello K (2010) How and why scholars cite on Twitter. Proc Am Soc Info Sci Tech 47:1-4

Priem J, Taraborelli D, Groth P, Neylon C (2010) alt-metrics: a manifesto. http://www.altmetrics.org/manifesto/. Accessed 8 July 2014

Priem J, Costello K, Dzuba T (2012) Prevalence and use of twitter among scholars. http://www.figshare.com/articles/Prevalence_
and_use_of_Twitter_among_scholars/104629. Accessed 26 May 2014

Research Information Network (2010). If you build it, will they come? How researchers perceive and use web 2.0. Research Information Network, London

Roman L (2014) Using social media to enhance career development opportunities for health promotion professionals. Health Promot Pract 15:471-475

Rowlands I, Nicholas D, Russell B, Canty N, Watkinson A (2011) Social media use in the research workflow. Learn Publish 24:183-195

Smith C (2014) How many people use $600+$ of the top social media, apps and digital services? http://www.expandedramblings.com/ index.php/resource-how-many-people-use-the-top-social-media/ \#.VCqkbhYze3F. Accessed 26 May 2014

Sumners C (2010) Social Media and Scientific Journals: a Snapshot. Sci Editor 33:75-78

Terras M (2012) Is blogging and tweeting about research papers worth it? The verdict. http://www.melissaterras.blogspot.ch/ 2012/04/is-blogging-and-tweeting-about-research.html. Accessed 26 May 2014 